Comparative Philosophy Volume 12, No. 1 (2021): 170-183

Open Access / ISSN 2151-6014 / www.comparativephilosophy.org

https://doi.org/10.31979/2151-6014(2021).120114

CONSTRUCTIVE-ENGAGEMENT DIALOGUE

PHILOSOPHY OF MIND

AUTHOR MEETS CRITICS:

\title{
IS THE SELF REALLY THAT KIND OF ILLUSION?
}

\author{
ANAND JAYPRAKASH VAIDYA
}

ABSTRACT: Karsten Struhl has offered an intriguing account of what kind of illusion the self is. His account is based on Buddhist philosophy, neuropsychology, and neuroscience. This critical notice examines his arguments, and aims to question whether or not the self is the kind of illusion Struhl argues it to be.

Keywords: Buddhist Illusionism, Cognitive Penetration, Karsten Struhl, neuropsychology, self

\section{WHAT IS BEING DENIED BY BUDDHISTS?}

Karsten Struhl's, "What Kind of Illusion is the Illusion of the Self?" is a delightful examination and defense of Buddhist illusionism about the self. In particular, it is about how Buddhist illusionism about the self can be understood by looking at some ideas about the self and illusions in neuropsychology and neuroscience.

The point of departure for Struhl's view is an account of what Buddhists deny when they announce the doctrine of no self (anattā). After listing out different notions of the self, he maintains the following:

These various features are interwoven into our general concept of the self. Thus, what is being denied by Buddhism is the existence of a substantial, unchanging, independent and unitary entity with an essential core which is both the subject and possessor of my experiences and body, while yet distinct from them, which separates what is me from what is not me, and which is also the agent that controls my actions, desires, and thoughts. The belief that we have such a self is for Buddhism, a cognitive illusion. (Struhl 2020, 115; emphasis added)

VAIDYA, ANAND JAYPRAKASH: Professor of Philosophy, San Jose State University, USA. Email: anand.vaidya@sjsu.edu 
Without specifying a specific school or thinker in a school it is often hard to say what "Buddhists" believe. While I find Struhl's account of Buddhism familiar from various sources, I am worried that this account of what Buddhism denies is vague in so far as it does not specify enough thinkers from various schools and what their specific arguments were. If there is a core to what Buddhists deny, across all schools, I would be inclined to say that it is what Hindus claim there is: a permanent self. Something that exists at all times. All Buddhists deny that. Even if the Buddha, arguably, does not explicitly say it. And if there is a close second that all Buddhists deny, it would be that we have complete cognitive control over our decisions and actions, something Struhl does discuss via a specific thinker. However, whether they all think the self is momentary or that there is no subject of experience at a given moment is something that varies across schools. While both Abhidharma and Yogacārā are anti-realist schools of a certain kind, Yogacārā is much different than its predecessor Abhidharma. Surprisingly, Struhl emphasizes our conception of the self, but Buddhists weren't engaging our (modern) concept(s). Rather, they were rejecting Hindu conceptions at first, which involve the notion of permanence.

As Struhl notes there are about nine different notions of the self that a Buddhist from a specific school could be denying. My reason for bringing this list up is that it seems that the reasons that go into showing that one kind of self is an illusion don't automatically transfer over to saying that another kind of self is an illusion. For example, just because there isn't a permanent self across time, it won't follow that there isn't an independent self for some portion of time. Of course, the doctrine of dependent origination helps us see how the independent self is an illusion, but that doctrine doesn't show us that there isn't a permanent self across time. For example, if everything is permanent, because change is the illusion, yet dependent, then we have a model on which independence is an illusion, but permanence is not. Definitions matter, and there are subtle arguments that need to be made. So, when one wants to argue that the self is an illusion it is important to keep two things in mind. First, what notion of the self is at stake. Second, what kind of illusion is in play. Struhl is careful to do that. However, at least with respect to the first notion, that of the self, I worry that he assumes a notion of the self that really isn't articulated in totality or argued against in totality by any one thinker or school of thought in Buddhism, maybe Nāgārjuna, but I doubt it.

Nevertheless, Struhl is operating with a familiar picture that is popular in Buddhist Modernism, as discussed for example in Evan Thompson's recent Why I am not a Buddhist. ${ }^{1}$ My point is that showing that the self isn't permanent in time, because everything changes, or that the self isn't independent, because everything is dependently originated isn't sufficient for showing that there is no controller self or subject of experience that last longer than a moment. Arguments that show one kind of self is an illusion often times don't transfer over to other notions of the self. Struhl needs a battery of arguments that are consistent with one another to show that his notion of the self is completely an illusion.

\footnotetext{
${ }^{1}$ See Thompson 2020.
} 
Finally, it is important to say something about a popular Buddhist argument against the existence of a permanent self, the argument from changing parts. ${ }^{2}$ According to this argument there are five aggregates that constitute an individual person. And importantly, as Struhl points out, Buddhists hold that these five aggregates are exhaustive. There is nothing to an individual person that cannot be accounted for via the five aggregates. It is then argued that since the parts all change over time nothing is permanent in time. This is a great argument, and it bears deep reflection. But it is open to a direct attack that is very clear.

Some Buddhists move as follows: if there are only five parts and all of them change at some time, then there is no permanent self. But one can simply accept the conclusion and move to the following adjusted position. All the parts change and there is no permanent self, but there is a semi-permanent self that is not identical to one of the five parts, since we need to account for cognitive control and decision making, and diachronic knowledge. On my view Buddhists were correct to criticize Hindu schools for thinking there is a permanent self, like a soul, that exists at all times. But from that fact it won't follow that there is no kind of self that remains, which has some of the relevant properties, such as control, in a semi-permanent way. The move some Buddhists make holds that there is no permanent self, since each of the five parts changes over time. But: couldn't there be a semi-permanent self, something that exits for longer than a moment, and for less than all time? For example, Husserl, see his phenomenology of internal-time consciousness ${ }^{3}$, tells us that time consciousness has a pro-tension and re-tension structure, which must have a duration. Couldn't an investigation into the phenomenology of time be used as an argument that goes against the no duration view of momentariness? Of course not every Buddhist will fall victim to Husserl's position, since momentariness is important for Abhidharmikas, but might not be for Madhyamikas.

Once again, on the view I advocate, the self is a phase of a person. Something that exists for some amount of time, but not for all time, and is subject to change as well, but serves other important cognitive roles during each phase, such as decision making and being the subject of experience, accounting for diachronic knowledge, such as when one touches what they saw over time and recognize that it is the same thing. ${ }^{4}$ Moreover, we can grant that Buddhists have a great argument against Hindu schools that defended a permanent unchanging self. But those arguments fall short of showing that there is no sense of self at all that has some duration in time, longer than a moment and less than forever. I am confident that some Buddhists would respond to my arguments and my position by pointing to the doctrine of two truths, where there is a distinction between what is conventionally real and what is ultimately real. I grant that Buddhists would point out that my view is one that is only conventionally real, but not ultimately real. I would challenge them to provide a semantics for the truth predicate that is consistent across a two-level view.

\footnotetext{
${ }^{2}$ See Pesala 2009.

${ }^{3}$ See Husserl 1928/1964.

${ }^{4}$ See Chakrabarti 1992.
} 


\section{WHAT KIND OF ILLUSION?}

Struhl argues that there are many types of illusions. He distinguishes between three kinds of illusions.

Motivational illusions are false beliefs that are not based on evidence, but rather by our desire for them to be true. If I believe that the Chicago Bears will win the superbowl in two years, simply because I desire it, and not based on any evidence, then what I believe is an illusion in the sense of how it is motivated. Cognitive illusions, are false beliefs about the fundamental nature of reality that are unexamined by most of us, and they are very difficult to dislodge. Moreover, they don't arise simply due to our desires. Even though I believe that space is flat because it looks that way, contemporary physics tells me that it is curved. Yet, it is really easy for me to fall back into that belief in many contexts. Thus, I am under a cognitive illusion. Phenomenal illusions, in contrast to the other two, are not beliefs, but on Struhl's account they often lead to beliefs. Struhl's example of a phenomenal illusion is the Kanizsa-square illusion, figure 2 below. Because there is no square present, but most of us see one.

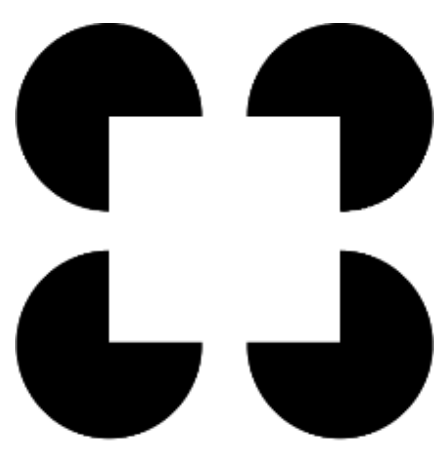

Figure 2

I will speak about phenomenal illusions at length in the final section. For now, I want to take note of a disagreement between Struhl and I about his categorization of the three types of illusions.

Concerning these three types, Struhl says the following.

While analytically, it is useful to keep the three senses of illusion separate, they will in practice often be conjoined. Beliefs motivated by strong wishes are often strongly supported by cognitive illusions, and such cognitive illusions are often generated by basic intuitions or feelings based on the way our mind organizes our experiences. Thus, if the self is an illusion, the belief that it exists may be derived from basic human wishes, reinforced by beliefs that are cognitive illusions, and grounded in our phenomenal intuition of self, what may be called our "I" sense, that cannot be dissolved without the aid of special meditative techniques. (Struhl 2020, 120) 
I find this quite troubling. I think that the former two notions are not even illusions. The core notion of "illusion" that I take seriously is perceptual and based on the classical Indian philosophical notion of something being presented other than it is, which is much discussed by the $13^{\text {th }}$ century father of Navya-Nyāya, Gangeśa. ${ }^{5}$ Let's take a familiar example from Vedānta and Nyāya, the rope that is perceived as a snake, the rope-snake case.

The rope is what is, while the snake is what I see; thus the rope is presented otherwise than it is to me. I have the illusion that a snake is there because the rope is presented otherwise. Freudian illusions, which Struhl appeals to in his account of motivational illusions, is, for me, a misuse of the term 'illusion'. When I believe without evidence that the Chicago Bears will win in two years, we have a case of hope or faith. I have faith, against the odds, that they will win, or I hope that they will win, against the odds I have examined, but not appraised rationally. But if I have appraised the evidence, then I don't have a belief in the proper sense. I have something belief like bordering on hope. Cognitive illusions aren't illusions for me either. Rather, they are just states of mind we deploy in various navigational activities. For example, they are states of mind that have a utility for us. Struhl doesn't defend why they must be labeled as beliefs. Simply put, neither motivational nor cognitive illusions are illusions for me. And that is significant for the purposes of investigating whether or not the self can be an illusion in a certain sense. For the self to be an illusion, on my account, it has to be the case that there is something that is presented otherwise to a subject of experience.

To make this clear, consider the following claims using the rope-snake case as the paradigm.

1. The rope is real, and presented otherwise as a snake to my consciousness.

2. The impermanent self* is real, and presented otherwise as permanent to my consciousness.

3. The dependent self* is real, and presented otherwise as independent to my consciousness.

4. The uncontrolled, undeciding self* is real, and presented otherwise as a controlling and deciding mind to my consciousness.

If self*, understood here as an impermanent-dependent-uncontrolling process ${ }^{6}$, is real, and the properties of permanence, independence, and control are what are presented otherwise to my consciousness, we need to ask: how is that magic trick done? For example: when in my conscious experience do I ever experience the self as permanent and existing at all times? For me to experience that, I would have to be monitoring something all the time, but I am not. Furthermore, if the analogy with the rope-snake case holds, then the illusion works as follows. The rope is real, the snake the illusion to my consciousness. So, the impermanent self* as process is real, and

\footnotetext{
${ }^{5}$ See Phillips 2011.

6 'Self*' is not a notion of the self that Buddhists are engaging. It is just a position that I am using to get a version of how the analogy with the rope-snake case might go, by having something, self*, with certain properties, being presented otherwise.
} 
permanence as a property is the illusion presented to my consciousness. But if that is how it goes, I must experience in my consciousness, directly and not by inference, the permanence, just as I do the snake. But just as Hume doubted that anyone perceives themselves constantly when they look inside ${ }^{7}$, I doubt anyone has the experience of sensing their permanence in time. If you are not constantly monitoring yourself and you don't exist for all times, how do you perceive that? It would be like saying even when you are not looking at the rope, you still see the snake-illusion.

Likewise, if the dependent self* is real, and the independent self is presented otherwise to my consciousness, then I should be able to experience the independent self, just as I do the snake. But do I experience the independent self? I clearly experience myself as both dependent and independent. I am born attached to my mother. I experience that phenomenally and non-conceptually when I was feeding in my mother's womb. I am raised with others around me who I am "dependent" upon both in my everyday engagement, movement, and guidance, as well as legally. When do I experience myself as an independent self? Maybe in America where rugged "individualism" is at play, one does experience an independence as an adult who has a job and is living away from their nuclear family. But that doesn't seem to be what the Buddhist were up to. Maybe I experience myself as independent in the sense that I don't feel myself attached to anyone. But that trades on an error. I don't feel physically attached to anyone, but I do feel emotionally attached to many people in a dependent way. Maybe it is a metaphysical point Struhl is after. From an adult reflective and phenomenological point of view I experience myself as a three-dimensional object that is wholly present at a given time. Maybe that is the sense in which I experience my independence. However, this also seems wrong. Since I don't really experience that. Rather, I experience being me, and relative to a definition of 'dependence' and 'independence' I can analyze myself as falling into one of those categories. But I surely don't have the illusion of being independent in the way in which I have the illusion that there is a snake before me, which is present directly in my experience without analysis. It is activated by my fear of snakes, and it controls my navigation, even though it is an illusion. Just because I see myself as an object with boundaries doesn't mean that I am independent of other things. All the states in the US have a boundary, they are still dependent on the American Government.

Finally, if complete control is the illusion based on something that has no control, that is odd. In order to have the concept of control, I have to acquire it from something where genuine control is present. However, if genuine control isn't present in the self at all, then it isn't present anywhere. If no one has self-control, then no one exerting control on others is controlling them. Control can only come from an agent, and if all agent's lack control, then there is nothing that answers to the concept of control, so how would I have got the concept so that I have an illusion of it? Note: to have the illusion of a snake, I should have experienced snakes before. And to have the illusion of a hare with horns, I at least have to have an experience of the parts, hares and horns, which I then recombine in my imagination. So, how do we get the concept of complete control,

\footnotetext{
${ }^{7}$ Hume 1739/2003.
} 
such that something which has no control can present it to their own consciousness? Perhaps, we did it by extrapolation on analogy with the hare with horns case. For example, we generated a concept of complete control by extrapolation from limited control. What we experience is limited control, and what we extrapolate is complete control. But can this really make sense, if the view is that control is an illusion. Wouldn't limited control have to be an illusion as well? While one can concede that complete control is an illusion, it seems difficult to say that all control is an illusion. And if we have at least limited control, what is the point of showing that control is an illusion. For, if we are dependently originated, then it would seem that we only could have limited control. Furthermore, while phenomenology might lead us to think we have complete control sometimes, reflection reveals to some that we have limited control and not complete control. For when does anyone actually feel like they have complete control? Don't we generally concede that whatever control one has at a moment is based in part on prior conditioning, and as a consequence is limited by it. If that holds, then what needs to be shown to be an illusion is limited control.

In a way my questions are intentionally juvenile. I want to show how jarring Buddhist illusionism can sound to ordinary reflection. I grant that it might be liberating, but it is also jarring.

Struhl reaches out beyond Buddhism to makes sense of the illusion of the self he finds in it. He reaches out to contemporary philosophers, such as Thomas Metzinger, who is deeply informed by cognitive neuroscience. He finds Metzinger's flightsimulator analogy telling, helpful, and a support for illusionism about the self that resonates with Buddhism. Here is a central claim about the self as an illusion that Metzinger makes.

The human brain can be compared to a modern flight simulator in several respects. Like a flight simulator, it constructs and continuously updates an internal model of external reality by using a continuous stream of input supplied by the sensory organs and employing past experience as a filter....For us, phenomenal reality is not a simulation space constructed by our brains...[I]t is the world we live in. It is virtually hidden, whereas a flight simulator is easily recognized as a flight simulator. (Metzinger 2009, 107)

Here is a simple question I would like to raise for Metzinger and Struhl. If the self is an illusion modeled on the flight simulator as described above, how does anyone know that? What is the theory of diachronic knowledge that allows one to say: there are no selves, such that someone has come to know that and can tell that to all these other things that don't have selves? Where is the knowledge based when it is acquired by Metzinger, and to whom is it transmitted? Is the base an illusion as well? It is common sense to think that when I go to school to learn something, and pass an exam, that it is me who knows. By this 'me who knows' I mean that were I to be downloaded onto a computer and transferred from my brain to another brain I would only be the same person if the brain to which I was transferred also had the same knowledge and skills to a reasonable degree of similarity (say $85 \%$ preservation). Brains house selves, but selves are not identical to brains, since neurological parts change over time while 
selves remain the same through some of these changes. The flight simulator makes sense, because there are entities outside of it, that are not flight simulators that can interpret them in a way that makes sense of the illusions they use to be simulators.

On my view, simulators have derived intentionality, not original intentionality. What do these terms mean? Words have derived intentionality. The word 'cat' refers to cats in English and is about cats because certain people, English speakers, use the word that way. The people that use 'cat' that way have original intentionality, the power to make the word 'cat' refer to cats and be about cats. Simulators have derived intentionality because, we created them to simulate something, flight. We have original intentionality, simulators have derived intentionality. Moreover, it is metaphysically impossible for there to be illusions all the way down. I believe in the asymmetric dependence of error on truth. For an illusion to occur, there must have been a nonillusion in the first place. While Buddhists might dislike this view, many members of the Nyāya school embrace it. ${ }^{8}$

\section{EXTINGUISHING THE ILLUSION OF THE SELF}

Struhl says, "Extinguishing the illusion of the self would require dispelling not just the attachment to the idea of the self at the cognitive level, but also the more primal appearance of self at the phenomenal level"' (2020: 129). Before I engage Struhl's work on extinguishing the illusion of the self, I need to reiterate the point from the prior section. Consider the rope-snake case again. From a distance I see the rope as a snake because ropes look similar to snakes objectively and my fear of the latter triggers a foul up in my perceptual processing such that I see a snake instead of a rope. However, that illusion fades as I come close. When I get close to the rope the snake illusion fades because the perceptual system cannot make the same mistake. The properties of the rope that differentiate it from a snake override the probability of the snake foul up, even though their tubular shape is objectively similar. When close, no snake illusion, when far, some probability of snake illusion, given a fear of snakes. In addition, there is a self for whom a snake was once perceived and is no longer perceived. The self, need not be permanent in time, independent of everything else in the world, or in complete control of all decisions. The self might simply be a phase of a person that can account for diachronic knowledge change, which is distinct from the five aggregates. We might call such a conception of the self: the epistemic agential self. Importantly, it is the base that accounts for an epistemic perceptual change from seeing a snake at location $l$ to seeing a rope at $l$ and revising one's beliefs in light of such a change. If this is plausible, we can directly ask in the case of extinguishing the illusion of the self: for whom is the illusion extinguished epistemically? For the extinguishing of an illusion is a case of diachronic knowledge change. Consider the analogy.

\footnotetext{
${ }^{8}$ Dasti 2012.
} 
Snake-illusion

1. $S$ is such that at $t_{1}$ a snake is perceived at $l$.

2. $S$ is such that at $t_{2}$ a rope is perceived at $l$.

3. In light of the change in what is perceived at $l, S$ comes to believe that she was the subject of an illusion based on a theory of illusion and what is perceived at $l$ at $t_{2}$.

\section{Self-illusion}

4. $S$ is such that at $t_{1}$ a self is perceived at $l$ (within $S$ 's body).

5. $S$ is such that at $t_{2}$ no self is perceived at $l$ (within $S$ 's body).

6. In light of the change in what is perceived at $l, S$ comes to believe that she was the subject of an illusion based on a theory of illusion and what is perceived at $l$ at $t_{2}$.

In the snake-illusion it makes sense to say: $S$ came to believe that she was the subject of an illusion based on what she saw and a theory of illusion. By analogy, it would appear that we can say the following in the self-illusion: $S$ came to believe that she was the subject of an illusion based on what she saw and a theory of illusion. But if that goes through we have a problem. In the snake-illusion I would say that $S$ is a self that had an epistemic change in light of perceptual change. By analogy, I would then say, $S$ is a self that had an epistemic change in light of perceptual change. But then: for whom has the illusion of the self been extinguished? Perhaps, Struhl is inclined to say that the $S$ that remains is merely a function of grammar alone. The analogical argument only looks strong because of grammar, the subject-predicate form. I concede that this response is available. However, it is not convincing. For independently of grammar, I have argued that there are epistemic subjects, epistemic selves, who can undergo a change in view. Diachronic knowledge change is real. So, although the grammar of how I am writing favors my position, the mere fact that the grammar does so is not an argument against the view. What is needed is a powerful epistemology, one that Buddhist philosophers, such as Vasubandhu, Dignāga, and Dharmakīti developed and defended. Struhl's work could be more complete were he to reference and engage these thinkers as well as their contemporary commentators, such as John Dunne. ${ }^{9}$

A final comment I will make on the epistemic self aims to address Struhl's use of Robert Wright's description of Buddhism. Struhl notes that Wright ${ }^{10}$ holds to the view that Buddhism should be described as "the view from nowhere," a term also used by Nagel $^{11}$ as the title of one of his books, something Struhl is aware of. But Wright's description of Buddhism pivots into the problem I am raising. Use of 'the view from nowhere' leads to explicit confusion. The view from nowhere is an abstraction from

\footnotetext{
${ }^{9}$ Dunne 2004.

${ }^{10}$ Wright 2017.

${ }^{11}$ Nagel 1986.
} 
actual views upon views. A three-dimensional creature, such as a human, can look upon a two-dimensional creature, ${ }^{12}$ and say of them, "wow they can only move in two dimensions." By abstraction a three-dimensional creature can imagine a creature in four-dimensions looking down upon them and observing the limitations of their viewpoint. And the analogy can continue infinitely and asymptotically toward a limit point that is never reached. The idea of a limit point of view increasing perspectives as an abstraction is a view from nowhere. However, actual creatures, not abstract ones, as the Jains taught us, always have a view from somewhere or somewhen. I don't think that Buddhists would sign up for a view from nowhere. Do Buddhists really advocate the view that because we don't actually have a self that is permanent and unchanging in time each of us is a view from nowhere?

Let me now move on to Struhl's important claims about extinguishing the illusion of the self by modeling it on the Kanizsa-square illusion. Here is his hypothesis:

Perhaps what happens as we move further along the path is that we oscillate between first seeing the illusion of the Kanizsa square, then, by careful attention, seeing that the square does not exist; and then, as we step back from our attentional focus, once again seeing the square even though we know cognitively that it does not exist. Through the careful attention of vipassana, again in conjunction with other Buddhist practices, we can come to experience a sense of selfless ness that can carry over and frame our experience outside of meditative practice for a time. However, even as we move considerably along the path to enlightenment and Nirvana, the sense of self returns at least at the phenomenal level, just as the Kanizsa square illusion returns when we step back from close attention to the spaces between any of the four black figures. (Struhl 2020, 133)

Without a doubt this is an interesting hypothesis. John Dunne once showed an audience at Berkeley (Siderits was there) how the Kanizsa-triangle Illusion is cognitively penetrable, figure 2 below.

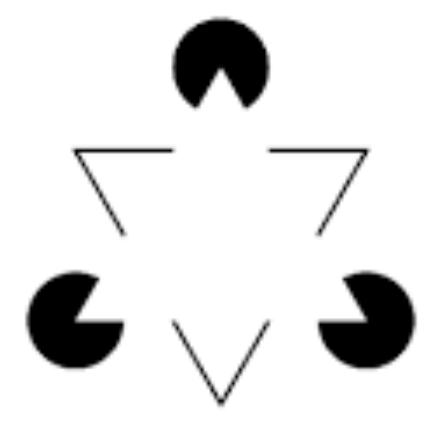

Figure 2

For many, when they first look at the array of figures, a triangle pops out at them. But if they know what a pac-man figure is, and they repeatedly say to themselves, "pac-

\footnotetext{
${ }^{12}$ Two-dimensional creatures are described and discussed in relation to three-dimensional creatures in Edwin Abbot's Classic, Flatland (1992).
} 
man," eventually they extinguish the triangle figure, and see three pac-men approaching the center. In another variation, if they know what a pizza pie looks like, and they repeatedly say to themselves, "pizza slice," they can come to see three pizzas, each with a missing slice. So, in the Kanizsa-triangle figure we have cognitivepenetration along the axis of occurrent thoughts changing what we see. Nothing important about cognitive penetration hangs on the difference between the triangle version and the square version of the illusion. Now consider the Muller-Lyer illusion, figure 3 below.

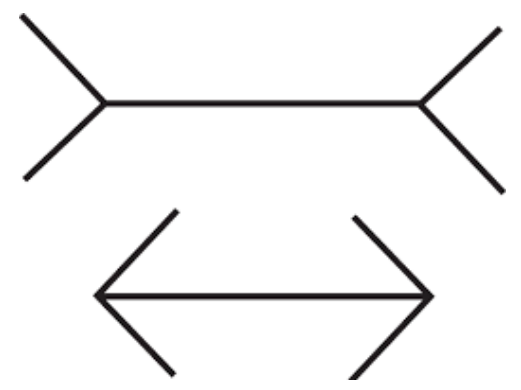

In the Muller-Lyer illusion no matter what we think, or come to believe, we will see the lines as being of unequal length when they are in fact of equal length. Struhl wants to say that the illusion of the self is like the Kanizsa-square illusion, subject to cognitive penetration in a robust way, as opposed to the Muller-Lyer illusion, which is cognitively impenetrable for the most part. ${ }^{13}$ Aare there any important differences between these two illusions at the cognitive-phenomenal border? Here is a hypothesis.

The Kanizsa figures are completion illusions. In a completion illusion the perceptual system takes information at one level of processing, prior to conscious perception, and presents to consciousness the thing that is most likely to be out there in the world, given the input and prior experience. In both the square and triangle case, the relevant closed figure is pretty much there. So, given prior experience and Bayesian inference through predictive processing, the system throws up to consciousness the relevant closed figure. The main point is that something is completed based on the input.

The Muller-Lyer lines are not completion illusions, everything is there. Rather, when I ask you, "are the lines of equal length?" you judge that they are not because the arrow edges lead you to see the internal lines as being of different length. But you don't complete any figure. In completion illusions cognitive penetration occurs in a concept dependent way. If you possess the relevant concepts, pac-man and pizza slice, then given the relation between these concepts and the perceptual array you can change what you see. There is a mapping between the perceptual array and the concept. However,

\footnotetext{
${ }^{13}$ I say for the most part because some people are not subject to the illusion at all. They don't see the lines as being of unequal length, whether or not they see them as the same length. There is cultural variation on the Muller-Lyer illusion, but that cultural variation is not the same as conceptual variation in the Kanizsa Square or Triangle illusion, here the illusion is dependent on having the concept of a square or triangle. You won't see the square or the triangle if you don't possess the relevant concepts.
} 
in the Muller-Lyer illusion cognitive penetration cannot occur, since there is nothing to complete, and the question is about length.

Struhl thinks that the illusion of the self is like the Kanizsa-square illusion. We can phenomenally pop in and out of seeing the illusion. I would prefer to say that we can go between different things we see on the model of the triangle to pac-man change based on cognitive penetration. I will concede to Struhl that this can occur. But I want to close my comments by challenging the propriety of this illusion as a model for the illusion of the self. Before I do that, I will simply note the worry from before. The Kanizsa figure illusions are illusions relative to a conscious subject with an epistemic self with concepts that can undergo diachronic knowledge change. Who is the illusion of the self an illusion for? I am sure Buddhists think that I am drastically confused, so I will move on to another worry.

Look carefully at the Kanizsa-triangle illusion. No! Look very carefully. Do you really see a closed figure that is a triangle? No! You don't! What you see is a cognitive completion of a perceptual array that remains incomplete in your perceptual field. You see the corner bounded parts of the triangle with space for each of the three sides. You don't perceptually complete. You cognitively complete. Better yet, your perceptual array suggests cognitively to you a completion. And when you are queried as to what you see before you, you answer, "triangle." So, if the illusion of the self is something we can move in and out of, like we can in the Kanizsa figure illusions, we need to get clear on how this could work. Consider the two cases.

Kanizsa-triangle illusion

1. $S$ is such that at $t_{1}$ a triangle is perceived at $l$.

2. $S$ is such that at $t_{2}$ no triangle is perceived at $l$.

3. In light of the change in what is perceived at $l, S$ comes to believe that she was the subject of an illusion based on a theory of illusion and what is perceived at $l$ at $t_{2}$.

\section{Self-illusion}

4. $S$ is such that at $t_{1}$ a self is perceived at $l$.

5. $S$ is such that at $t_{2}$ no self is perceived at $l$.

6. In light of the change in what is perceived at $l, S$ comes to believe that she was the subject of an illusion based on a theory of illusion and what is perceived at $l$ at $t_{2}$.

Putting aside the illusion for whom complaint, we are now in a position to look at two other problems. In the Kanizsa-triangle case I don't simply fail to see a triangle, I also see something else, maybe pac-men figures, if that is what I have been thinking about, but minimally the three circular figures with a missing piece. If the self-illusion is modeled on the Kanizsa figures, it must be the case that I see the self, such that it can be a perceptual illusion that is extinguished. But, again, as Hume correctly taught us, 
when we look inside, not perceptually, but introspectively, we don't see a self -a permanent thing in time, we see a bunch of changing phenomena. So, we don't even see the thing that is the illusion that is supposed to be extinguished. But now let us suppose that we do. We face another problem. When we stop seeing the Kanizsatriangle, there is still something that we see, maybe pizza slices, if we are hungry. What is it that we see when we stop seeing the self, even if only for 30 seconds, because according to Struhl, we pop in and out of the illusion? Perhaps some Buddhists will answer that we see the organized behavior of the aggregates arising and passing away. But this seems to miss the mark as well, since when we look inside, as Hume instructs us to do in our search for the permanent self, we already see a bundle of states arising and passing away. What is all the work for, if what Hume tells us to do gets us there directly.

To sum up. In the Kanizsa-triangle we do see a triangle (in a way) and it goes away, by repeating 'pac-man' over and over again. Suppose there is some mantra that helps the phenomenal illusion of the self disappear. First, we don't ever seem to see that. There appears to be a category mistake in the analogy. Second, when the mantra extinguishes the supposed illusion of the self, what is it that we then come to see. In the Kanizsa-triangle case we see pac-men. What about in the illusion of the self case? Please don't say the view from nowhere.

I don't find the Buddhist account of the self as an illusion compelling at all, because I don't think there is an illusion of the self, although I think there might be a metaphysical error in the Hindu account of the self as permanently unchanging. I do think Struhl has done a wonderful job trying to make sense of the position by taking a cross-cultural and multi-disciplinary approach and making it publicly accessible. I take his work to be an excellent example of effortful publicly engaged cross-cultural and multi-disciplinary philosophy. While the arguments and questions here are critical, they come from a place of deep respect for the traditions and disciplines engaged. I often find myself walking around in a circle thinking about Buddhist illusionism and wrestling with the power of it. And Struhl works hard in his essay to bring an account of their doctrines to the public in an accessible way.

Finally, while many have argued that metaphysics is necessary for soteriology, at times I wonder if it really is. Easing suffering is about practices, which need not be so

much about believing whole doctrines and ontological views of the world, as they simply might be about practices that do ease an individual's suffering; be that heavy metal band practice or group mindfulness meditation. Thank you Karsten!

\section{REFERENCES}

Abbott, Edwin (1992), Flatland: A Romance in Many Dimensions (New York, USA: Dover Publications).

Bhikku Pesala (2009), The Debate of Kind Milinda (Delhi, India: Motilal Banarsidass Press). 
Chakrabarti, Arindam (1992), "I touch what I saw", Philosophy and Phenomenological Research 52.1: 103-116. < https://doi.org/10.2307/2107746>

Dasti, Matthew (2012), "Parasitism and Disjunctivism in Nyāya Epistemology", Philosophy East and West 62.1: 1-15. <https://doi.org/10.1353/pew.2012.0012>

Dunne, John (2004), Foundations of Dharmakirti's Philosophy (Massachusetts, USA: Wisdom Publications).

Hume, David (1739/2003), A Treatise of Human Nature. (New York, USAA: Dover Publications. See Sect. 6, Part IV, Book 1.

Husserl, Edmund (1928/1964), The Phenomenology of Internal Time Consciousness (tr. J. Churchill) (The Hague: Marinus Hijhoff).

Metzinger, Thomas (2009), The Ego Tunnel (New York, USA: Books).

Nagel, Thomas (1986), The View from Nowhere (Oxford, UK: Oxford University Press).

Phillips, Stephen (2011), Epistemology in Classical India: The Knowledge Sources of the Nyāya School (New York, USA: Routledge).

Thompson, Evan. (2020), Why I am not a Buddhist (Conneticut, USA: Yale University Press).

Wright, Robert (2017), Why Buddhism is True: The Science and Philosophy of Enlightenment and Meditation (New York, USA: Simon \& Schuster). 